Case Report

\title{
Symmetrical Peripheral Gangrene: A Rare Complication of Malaria
}

\author{
Naresh Kumar', Niraj Bohania ${ }^{2}, \underline{\text { Anuradha }}^{3}$ \\ ${ }^{1}$ Professor of Medicine \& Head of Pulmonary Medicine, Maulana Azad Medical College, New Delhi, India. \\ ${ }^{2}$ Senior Resident, ${ }^{3}$ Director Professor, Department of Medicine, Maulana Azad Medical College, New Delhi, India. \\ DOI: https://doi.org/10.24321/2349.7181.201915
}

I $\quad \begin{array}{lllll}\mathbf{N} & \mathbf{F} & \mathbf{O}\end{array}$

Corresponding Author:

Naresh Kumar, 125, B.L. Taneja Block, Department of Medicine, Maulana Azad Medical College, New Delhi, India.

E-mail Id:

drnareshmamc@gmail.com

Orcid Id:

https://orcid.org/0000-0003-4581-609X

How to cite this article:

Kumar N, Bohania N, Anuradha S. Symmetrical Peripheral Gangrene: A Rare Complication of Malaria. J Adv Res Med 2019; 6(3): 16-18.

Date of Submission: 2020-01-10

Date of Acceptance: 2020-01-31

\section{$\begin{array}{lllllllllll}\mathbf{A} & \mathbf{B} & \mathbf{S} & \mathbf{T} & \mathbf{R} & \mathbf{A} & \mathbf{C} & \mathbf{T}\end{array}$}

Symmetrical Peripheral Gangrene (SPG) is one of the very rare and devastating complication of malaria. We report a 45 -year-old gentleman who presented with fever and blackish discoloration of digits. Examination revealed mild splenomegaly, cold peripheries with dry gangrene involving bilateral fingers and toes. Investigations revealed thrombocytopenia and transaminitis. Rapid malaria test was positive for both Plasmodium falciparum and Plasmodium vivax. Patient was treated with antimalarials. Clinicians managing malaria should be more vigilant for this rare devastating complication.

Keywords: Malaria, Fever, SPG

\section{Introduction}

Malaria is one of the commonest infections seen in Indian population, which often presents with various complications but Symmetrical Peripheral Gangrene (SPG) as a complication of malaria is very rare. SPG is one of the devastating complications of malaria which is characterized by distal ischemic gangrene of two or more sites in the absence of large vessel obstruction or vasculitis. ${ }^{1}$ This is rarely anticipated during management of malaria patients. We report a 45-year old gentleman who presented with symmetrical peripheral gangrene, a rare complication of malaria.

\section{Case Report}

A 45-year-old man presented with seven days history of high-grade fever with chills and rigors. Patient developed blackening of his toes and fingers on the fifth day of fever which was associated with pain (Figure 1). There was no history of diabetes mellitus, hypertension, drug intake, recent trauma to limbs, exposure to cold, bleeding from any site, alcohol use, and smoking. Examination revealed pulse rate of 110 beats/ min, regular, bounding, with all peripheral pulses were palpable, blood pressure of $120 / 70 \mathrm{mmHg}$ (comparable in all four limbs), temperature of $101.2^{\circ} \mathrm{F}$ and respiratory rate of 20 breaths/ min. His peripheries were cold with dry gangrene involving bilateral fingers and toes. Respiratory, cardiovascular and abdominal system examination were unremarkable. Neurological examination revealed decreased sensations over gangrenous area. Clinical diagnosis of septicemia with symmetrical peripheral gangrene was kept.

Initial investigations (Table 1) showed thrombocytopenia, raised total leucocytes, prerenal acute kidney injury, transaminitis, increased FDPs and prolonged Prothrombin Time (PT). 


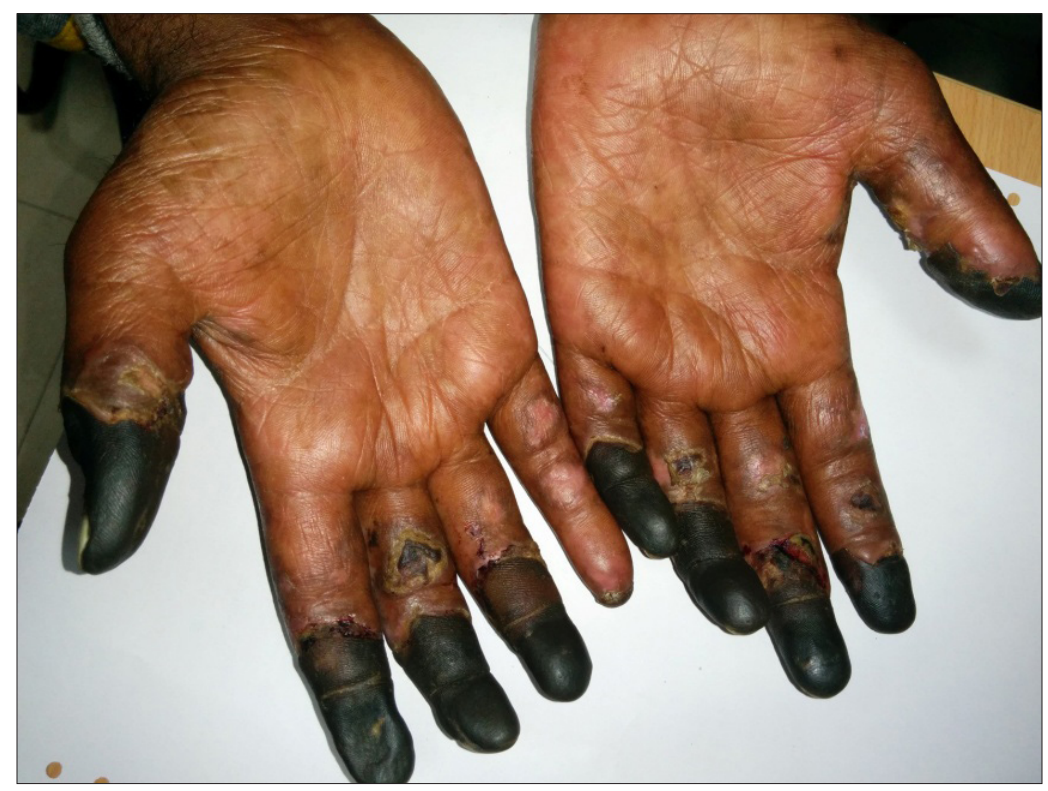

Figure I.Showing dry gangrene of all the digits in both hands

Table I.Investigations of the patient

\begin{tabular}{|c|c|}
\hline Parameters & Result \\
\hline Hemoglobin & $12.2 \mathrm{gm} / \mathrm{dL}$ \\
\hline Total Leukocyte Count (TLC) & $10200 / \mathrm{uL}$ \\
\hline Platelet count & $91,000 / \mathrm{mm}$ \\
\hline Blood urea & $64 \mathrm{mg} / \mathrm{dL}$ \\
\hline Serum creatinine & $1.3 \mathrm{mg} / \mathrm{dL}$ \\
\hline Total bilirubin & $0.6 \mathrm{mg} / \mathrm{dL}$ \\
\hline AST & $212 \mathrm{U} / \mathrm{L}$ \\
\hline ALT & $227 \mathrm{U} / \mathrm{L}$ \\
\hline Alkaline phosphatase & $170 \mathrm{U} / \mathrm{L}$ \\
\hline Random blood sugar & $110 \mathrm{~g} / \mathrm{dL}$ \\
\hline Putoimmune profile (ANA, dsDNA, Scl-70, APLA, U1RNP) & Negative \\
\hline HIV, HBsAg, Anti HCV Ab, Dengue serology & Negative \\
\hline Blood culture, urine routine and urine culture & Normal \\
\hline Chest x-ray & Normal \\
\hline Echocardiography & Normal \\
\hline Fibrin Degradation Products (FDPs) & Increased \\
\hline Prothrombin Time (PT) & 19 secs (Control-12 secs) \\
\hline Activated plasma thromboplastin time & 29 secs (Control-27 secs) \\
\hline
\end{tabular}

Rapid malaria dipstick test was positive for both Plasmodium falciparum and Plasmodium vivax. Arterial doppler of bilateral lower limbs revealed normal flow in the femoral and the popliteal, with slightly reduced flow in the dorsalis pedis with no distal flow bilaterally. In the upper limbs normal flow in the proximal arteries with diminished flow in the distal arteries bilaterally was noted.

Patient was treated with antimalarials (intravenous
Artesunate and Doxycycline). Clear line of demarcation appeared in the fingers. Patient was then referred to plastic surgery department for further follow up.

\section{Discussion}

Malaria is a mosquito-borne infectious disease which often presents with multiple complications especially in a case of Plasmodium falciparum (pf) malaria. Common complications 
of malaria include thrombocytopenia, acute kidney injury, acute respiratory distress syndrome, hepatitis, cerebral malaria (hypoglycemia, seizures), metabolic acidosis and hemolysis. ${ }^{2}$ SPG as a complication of malaria is very rare and it is described mostly in pf malaria cases. In our case there was dual infection with Plasmodium vivax and Plasmodium falciparum malaria. Few theories have been proposed to explain SPG in a case of malaria. In Plasmodium falciparum infections, heavy parasitemia stimulate complement system which in turns activate coagulation pathway leading to thrombosis of microcirculation resulting in peripheral gangrene. ${ }^{3,4}$ In another explanation, infected erythrocytes via intercellular adhesion molecule 1 (ICAM-1) get attached to receptors on capillary endothelium (cytoadherence). Infected erythrocytes stick inside and eventually block microcirculation leading to thrombosis and eventually gangrene. ${ }^{5}$ Various treatment modalities have been tried in SPG associated with malaria including anticoagulants, vasodilators, hyperbaric oxygen therapy etc. but none of them have been shown to be beneficial. ${ }^{6}$ In our case, we did not use any anticoagulants or vasodilators for SPG. According to the literature, mortality rate may be as high as $35 \%$ with rate of amputation ranging from $70 \%$ to $90 \%{ }^{7}$ Fortunately, outcome was positive in our case with almost full functional recovery of all four limbs.

Other causes of SPG include sepsis, low cardiac output states like dilated cardiomyopathy, vasopressor use, ergot poisoning but its association with malaria is rare. In our case, all the other possible causes of symmetrical peripheral gangrene were ruled out. Our patient remained hemodynamically stable throughout the course of the disease. The patient improved after receiving antimalarial therapy only which clearly indicates that malaria was the underlying cause of SPG in this case. SPG has been reported with Plasmodium falciparum as well as Plasmodium vivax malaria. ${ }^{8,9}$ However, our case had mixed infection with both.

To conclude, SPG is a rare complication of malaria and clinicians must be aware of this complication while dealing with cases of malaria.

\section{Conflicts of Interest: None}

\section{References}

1. Sharma BD, Kabra SR, Gupta B. Symmetrical peripheral gangrene. Trop Doct 2004; 34(1): 2-4. Available from: https://journals.sagepub.com/doi/ abs/10.1177/004947550403400102 [PubMed/ Google Scholar].

2. Nicholas JW, Joel GB. Malaria. In: Longo DL, Fauci AS, Kasper DL, et al, editors. Harrison's Principles of Internal Medicine. $18^{\text {th }}$ ed. McGraw Hill, New York. 2012; 1688-703.

3. Clemens R, Pramoolsinsap C, Lorenz R, Pukrittayakamee
S, Bock HL, White NJ. Activation of the coagulation cascade in severe falciparum malaria through the intrinsic pathway. Br J Haematol 1994; 87(1): 100-105. Available from: https://onlinelibrary.wiley.com/doi/ abs/10.1111/j.1365-2141.1994.tb04877.x?sid=nlm\%3A pubmed [PubMed/ Google Scholar].

4. Philips RE, Looaresuwan S, Warrell DA, Lee $\mathrm{SH}$, Karbwang J, Warrell MJ et al. The importance of anaemia in cerebral and uncomplicated falciparum malaria: role of complications, dyserythropoesis, and iron sequestration. Quart J Med 1986; 58(227): 305323. Available from: https://academic.oup.com/qjmed/ article-abstract/58/3-4/305/1560540? redirectedFrom =PDF [PubMed/ Google Scholar].

5. Ghosh SK, Bandyopadhyay D. Symmetrical peripheral gangrene. Indian J Dermatol Venerol Leprol 2011; 77(2): 244-248. Available from: http://www.ijdvl.com/article. asp? issn=0378-6323; year=2011; volume $=77$;issue $=2 ; \mathrm{s}$ page=244; epage $=248$; aulast=Ghosh [Google Scholar] .

6. Parmar MS. Symmetrical peripheral gangrene: a rare but dreadful complication of sepsis. CMAJ 2002; 167(9): 1037-1038. Available from: https://www.cmaj.ca/ content/167/9/1037.long [PubMed/ Google Scholar].

7. Ghosh S, Bandyopadhyay D, Ghosh A. Symmetrical peripheral gangrene: a prospective study of 14 consecutive cases in a tertiary-care hospital in eastern India. Journal of the European Academy of Dermatology and Venereology 2010; 24: 214-218. Available from: https://onlinelibrary.wiley.com/doi/abs/10.1111/ j.1468-3083.2009.03329.x [PubMed/Google Scholar].

8. Kumbhalkar S, Aher S, Wanjari S. Symmetrical peripheral gangrene: A rare complication of Plasmodium falciparum malaria. Ann Trop Med Public Health 2017; 10(1): 238-240. Available from: http://www.atmph. org/article.asp?issn=1755-6783; year=2017; volume= 10; issue=1; spage=238; epage $=240$; aulast $=$ Kumbhalkar.

9. Prabhat K, Ghazal T, Gupta H, Dixit J. Symmetrical peripheral gangrene in severe Plasmodium Vivax malaria. Indian J Crit Care Med 2017; 21: 245246. Available from: https://www.ijccm.org/doi/ pdf/10.4103/ijccm.IJCCM_424_16 [PubMed/ Google Scholar]. 